\title{
8
}
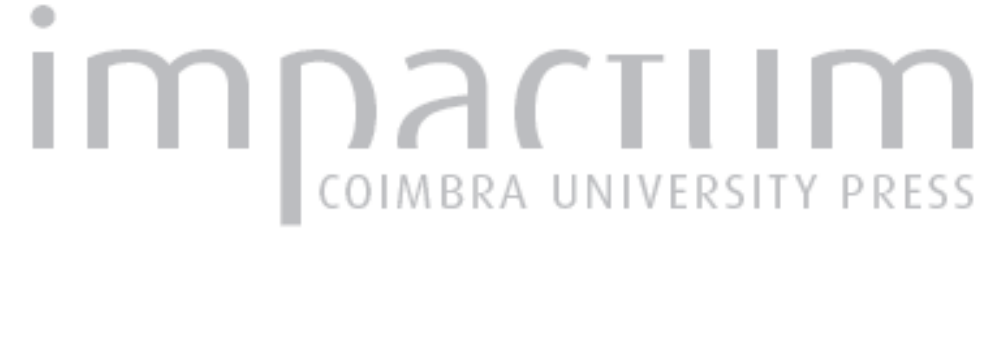

\section{Kant e a estética romântica germânica: da paisagem de Humboldt a geografia científica}

Autor(es): $\quad$ Barbosa, Tulio; Nunes, João Osvaldo Rodrigues Publicado por: $\begin{aligned} & \text { Universidade Católica de Petrópolis; Instituto Brasileiro de Informação } \\ & \text { em Ciência e Tecnologia }\end{aligned}$

URL

persistente:

URl:http://hdl.handle.net/10316.2/33056

DOI:

DOI:http://dx.doi.org/10.14195/1984-6754_3-1_5

Accessed : $\quad$ 26-Apr-2023 06:52:40

A navegação consulta e descarregamento dos títulos inseridos nas Bibliotecas Digitais UC Digitalis, UC Pombalina e UC Impactum, pressupõem a aceitação plena e sem reservas dos Termos e Condições de Uso destas Bibliotecas Digitais, disponíveis em https://digitalis.uc.pt/pt-pt/termos.

Conforme exposto nos referidos Termos e Condições de Uso, o descarregamento de títulos de acesso restrito requer uma licença válida de autorização devendo o utilizador aceder ao(s) documento(s) a partir de um endereço de IP da instituição detentora da supramencionada licença.

Ao utilizador é apenas permitido o descarregamento para uso pessoal, pelo que o emprego do(s) título(s) descarregado(s) para outro fim, designadamente comercial, carece de autorização do respetivo autor ou editor da obra.

Na medida em que todas as obras da UC Digitalis se encontram protegidas pelo Código do Direito de Autor e Direitos Conexos e demais legislação aplicável, toda a cópia, parcial ou total, deste documento, nos casos em que é legalmente admitida, deverá conter ou fazer-se acompanhar por este aviso. 

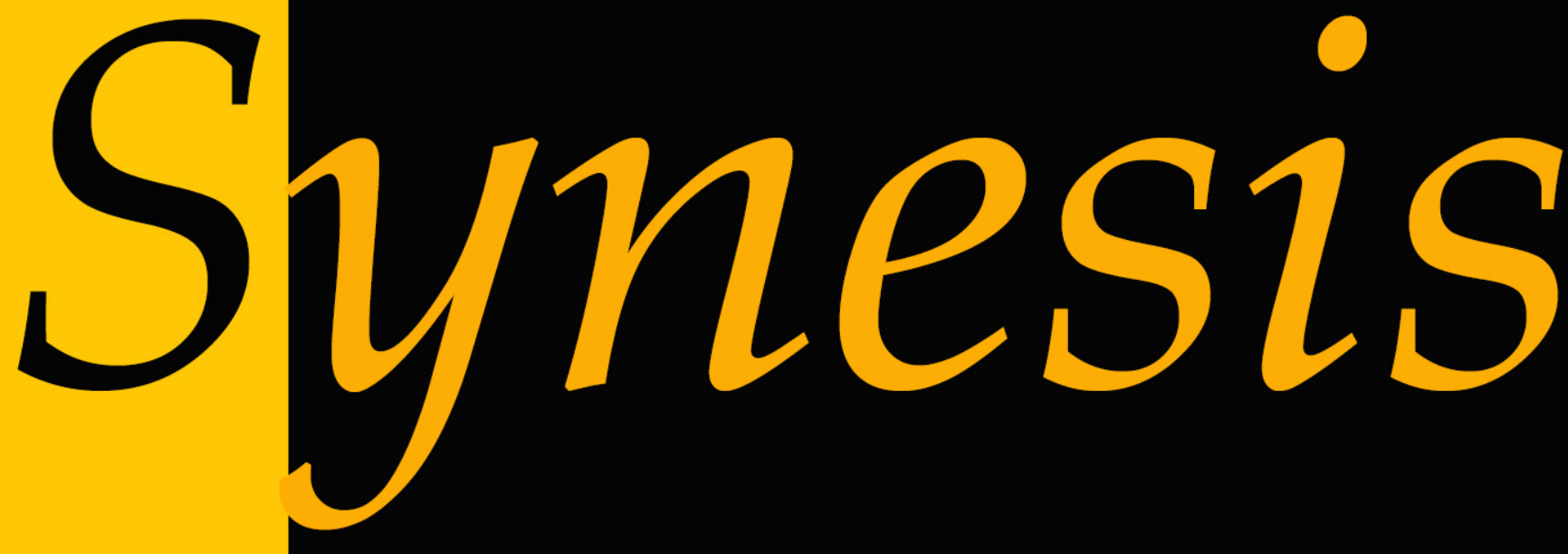

Revista do Centro de Teologia e Humanidades ISSN 1984-6754

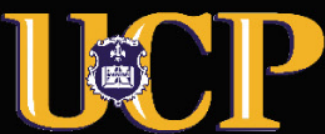




\title{
KANT E A ESTÉTICA ROMÂNTICA GERMÂNICA: DA PAISAGEM DE HUMBOLDT A GEOGRAFIA CIENTÍFICA ${ }^{1}$
}

\author{
Tulio Barbosa ${ }^{2}$ \\ João Osvaldo Rodrigues Nunes ${ }^{3}$
}

Resumo: O presente artigo é resultado da tese de doutorado (Estética Romântica Germânica e Geografia) na qual afirmamos a importância em compreendermos os elementos estéticos germânicos a partir de Kant, pois tais elementos proporcionaram o desenvolvimento da Geografia antecedida pela paisagem humboldtiana. Neste trabalho apresentamos argumentos que demonstrem nossa tese a partir da estética de Kant influenciadora direta na concepção estética romântica e o desdobramento para a cosmovisão de Humboldt que resultou numa estruturação estética singular objetivada na paisagem antecedida por essa herança subjetivada. Entendemos a paisagem náo apenas como categoria geográfica, pois o desenvolvimento da mesma resultou na edificaçáo da Geografia Moderna; assim, de Kant a Humboldt o caminho foi preenchido pelos ideais românticos que incitaram elementos constitutivos da liberdade, da individualidade e da criatividade, como consequência o desenvolvimento da Geografia.

Palavras-chave: Estética; romantismo; Kant; Humboldt; paisagem.

Resumen: Este artículo es el resultado de la tesis doctoral (La estética romántica alemana y Geografía) han enumerado la importancia de comprender los elementos estéticos de Kant, ya que estos elementos proporcionan el desarrollo de la geografía humboldtiana precedido por el paisaje. Nuestros argumentos demostrar nuestra tesis: el pensamiento de la estética de Kant influido en la estética y la visión del mundo romántico de Humboldt que dio lugar a una estructuración estética singular que se ha registrado en el paisaje objetiva y subjetiva precedidas por este herencia. Entendemos el paisaje no sólo como una categoría geográfica, porque su desarrollo ha dado lugar al establecimiento de la Geografía Moderna, así que desde Kant a la ruta de Humboldt fue agregado por los ideales románticos que llevó a los elementos constitutivos de la libertad, la individualidad y la creatividad, como consecuencia de la desarrollo de la Geografía.

Palabras clave: Estética; romanticismo; Kant; Humboldt; paisaje.

Abstract: This article is the result of the doctoral thesis (Romantic German Aesthetics and Geography) in which affirm the importance in understanding the aesthetic elements of the romantic german and of

\footnotetext{
1 Artigo recebido em 24/02/2011 e aprovado para publicação pelo Conselho Editorial em 18/05/2011.

2 Doutor em Geografia pela UNESP. Professor da Universidade Federal de Uberlândia - Campus Santa Mônica do Instituto de Geografia. Doutorando pelo Programa de Pós-Graduação em Geografia da Faculdade de Ciências e Tecnologia (FCT-UNESP). Currículo Lattes: http://lattes.cnpq.br/0987719839415557. E-mail: tulio@ig.ufu.br

3 Pós-Doutorado pela Universidad Alicante. Professor do Curso de Graduação e Pós-Graduação em Geografia da Faculdade de Ciências e Tecnologia (FCT- UNESP). Currículo Lates: http://lattes.cnpq.br/4756709773076464. E-mail: joaosvaldo@fct.unesp.br
} 
Kant, as these elements provided the development of geography humboldtiana preceded by the landscape. We present arguments to demonstrate our thesis of Kant's aesthetic has influenced the understanding of aesthetic and romantic worldview of the development of Humboldt, resulting in a structured landscape inseparable from the aesthetics. We understand that the landscape not only as a geographical category, because its development has resulted in the creation of modern geography, in order, from Kant to Humboldt the path was filled out by romantic ideals that led the constituent elements of liberty, individuality and creativity, result in the development of geography.

Keywords: Aesthetic; romanticism; Kant; Humboldt; landscape.

\section{INTRODUÇÃO}

Tencionamos apontar os elementos epistemológicos que compóe os fundamentos da Geografia Moderna, para isso, partimos da estética de Kant e do romantismo germânico até alcançar a cosmografia de Humboldt, que posteriormente, o desenvolvimento de suas metodologias quanto à observação resultou na fundação da categoria paisagem tal como conhecemos na ciência geográfica na atualidade.

Da paisagem cosmográfica para a paisagem geográfica somente foi possível através de Humboldt, esse caminho possibilitou o desenvolvimento da Geografia Moderna, pois Humboldt metodologicamente construir a Geografia atrelada à paisagem, posteriormente, a Geografia, enquanto ciência ampliou suas discussóes e suas atuaçôes científicas, deste modo, a categoria paisagem, como inaugural, teve incorporada ao seu cabedal as demais categorias e conceitos apresentados e desenvolvidos na atualidade pela ciência geográfica.

A atual dicotomia (Geografia Física e Geografia Humana) não estava presente nas discussões de Kant e Humboldt, pois apesar de ambos apresentarem posturas que ora privilegiavam um aspecto ora outro, não era a real intenção destes pensadores, já que o objetivo máximo era compreender o mundo e seus múltiplos problemas em escalas diferenciadas.

O pensamento kantiano influenciou os românticos que por sua vez influenciaram Humboldt. Tal influencia parte, inicialmente, da estética, já que a mesma proporcionou um novo olhar no e para o mundo. A estética, a partir de Kant (1993 e 2008), transformou, para os pensadores e artistas, o modo de entender o mundo via percepção do sujeito, já que o sujeito passa a ser compreendido não mais como isolado ou mesmo submisso as vontades das deidades, uma vez que o mesmo é entendido a partir de valores aprioristicos ou em outras palavras a carga natural no sujeito em consórcio com os valores 
morais moldaram o sujeito, isto é, mesmo o homem buscando sua liberdade, a anarquia social, não se desprende das amarras naturais e as convençóes referendadas socialmente.

Diante disso, a estética proporcionou uma liberdade relativa, já que a construção de elementos via estética significava (ainda significa) a edificação pela imaginação, na qual a criatividade é fomentada e posta em prática.

O olhar estético, desde Kant (2008), passando pelos românticos proporcionou a construção de uma nova cosmovisão a qual estava vinculada à importância dos indivíduos (enquanto sujeitos capazes de irem além das imposições naturais e sociais) e a postura destes indivíduos em apontarem as incongruências do e no mundo, buscando um maior equilíbrio; assim, a Geografia surge desta tentativa romantizada em edificar um novo mundo.

\section{DO NÚMENO E DO FENÔMENO DE KANT AO ROMANTISMO: UM CAMINHAR ESTÉTICO}

O pensamento filosófico de Kant faz-nos pensar o númeno incognoscível como ponto de partida para a compreensão do mundo, todavia o númeno não nos revela a totalidade, para isso faz-se necessário a compreensão dos fenômenos os quais se revelam e permitem uma revelação que vai além do que a aparência nos mostra, graças a capacidade avaliativa do númeno exposta pela sensibilidade. Assim, o sensível desperta a coisa em si através das únicas formas que somos capazes de entender: o espaço e o tempo (KANT 1993 e 2008).

O desafio de Kant esteve ligado à capacidade de compreender a relação entre a sensibilidade e a razão a partir dos dados incognoscíveis replicados a partir das sensaçóes percebidas pelas formas espaciais e temporais, neste sentido, Kant opera sua filosofia apartando-se da metafísica para alcançar o entendimento nítido do fenômeno, todavia, retorna, posteriormente, a metafísica como base segura para equilibrar as sensações e as percepções, já que para o filósofo a razão em si e por si não nos revela a compreensão total do mundo (LEBRUN, 1993).

Desta feita, a relação do mundo para com o sujeito nos é revelada mediante a nossa capacidade em conseguirmos avaliarmos as sensaçóes e as percepçóes ancoradas na racionalidade e no sentimentalismo. A separação funcional das sensações e percepçóes esbarra na compreensão do sublime e do belo, ao mesmo tempo em que esses elementos promovem a aparição (ou revelação) dos 
fenômenos. Se por um lado a comoçáo do sublime é o espanto do sujeito, por outro o encantamento do belo pode ser a finalizaçáo do próprio sujeito, já que o mesmo sob efeito "hipnótico" encanta-se a ponto de não mais distinguir o que é o belo e o que é a verdade. (KANT, 1993; LEBRUN, 1993).

Nesta relação númeno e fenômeno a solução de Kant foi encontrada com maior maestria e esclarecimento na terceira crítica (Crítica da Faculdade do Juízo) através do estudo e questionamento da estética e é exatamente a partir deste ponto que o pensamento filosófico ocidental e as ciências humanas em geral reassumiram o equilíbrio entre o mundo externo e o sujeito, nesta direção o romantismo surgiu como conseqüência direta deste posicionamento.

A contribuição de Kant para a construção do pensamento romântico e a conseqüente edificação da Geografia Moderna a partir de Humboldt parte da tentativa em relacionar o sujeito e o mundo externo, da coisa em si para o fenômeno, sem abandonar as formas da sensibilidade, a percepção e a racionalidade, deste modo, a estética é apresentada como aglutinadora destes elementos, como possibilidade de revelar, simultaneamente, a coisa em si e o entendimento fenomênico. A estética kantiana pela revelação do belo e do sublime fez com que as geraçóes do século dezenove compreendessem o mundo via metafísica, sem abandonar por completo a racionalidade.

A estética romântica parte, portanto, da filosofia kantiana, revelada em meio ao questionamento das antinomias do gosto e do belo, neste caso, sublinhamos o conflito como direcionador da construçáo e da delimitação do que é ou não belo. O conflito relaciona-se ao númeno que nos é apresentado como em si, porém essa "lógica" em si e por si nos mostra a direção que não podemos encerrar por si, já que a totalidade mundo depende dos eventos fenomênicos para serem compreendidos e; assim, esse conflito revela-nos, muito tempo depois, a harmonia. A antinomia estética de Kant é o conflito que se harmoniza, todavia, essa harmonia não garante a permanência imorredoura desta situação, já que a antinomia por si, em princípio e de fato, é dialética e somente dialeticamente podemos compreender.

As formas de entendimento partem da relação da sensibilidade e da percepçáo; assim, a analítica do belo em Kant (2008) é fundamental para entendermos a totalidade do mundo e "nosso papel e função nesta totalidade", ou seja, compreender o mundo é importante para que possamos também nos compreender. Kant (2008) buscou, portanto, compreender a estética como ponto fulcral na nossa condição humana, já que nos organizamos socialmente a partir do desejo de alcançar a plena beleza, harmonia e perfeição. Neste caso, Kant (2008) trabalhou com a estética como conceito revelador das 
relaçóes do númeno e do fenômeno, ou seja, o belo nos obriga a entendê-lo numenicamente e fenomenicamente, em outras palavras o belo é revelado através dos juízos a priori e dos juízos empíricos.

A partir deste ponto a questão central é qual a validade desta compreensão, qual a razão (e suas conseqüências) de perquirirmos o belo? Kant (2008) traça seus argumentos que vão ser dinamizados no romantismo, isto é, o retorno da metafísica como elo, e não mais dispersor, da racionalidade; assim, se por um lado a razáo aponta-nos o que de fato é belo, a irracionalidade, o impensado, também nos fornece subsídios inconscientes para determinarmos o belo. O belo, para Kant (2008), é impossível de ser conceituado; assim, a racionalidade que define o belo é o belo revelado empiricamente, ao mesmo tempo em que essa compreensão empírica do belo só é possível por causa da beleza em si que se revela independente de conceito. É importante percebermos o projeto crítico de Kant (2008) na terceira crítica, já que o objetivo maior é conduzir o conhecimento do patamar racional para o estético sem abdicar de nenhum destes elementos.

A condução do conhecimento racional até sua compreensão estética, por Kant (2008), é o caminho "natural" para a compreensão do mundo e de nós mesmos, já que tudo que enxergamos e tentamos classificar; nomear e entender depende da relação dialética entre o númeno e fenômeno, isto é, a coisa em si (o objeto em si e por si) náo pode ser compreendida, ao contrário da beleza que em si é revelada, mas quando tentamos compreende-la optamos por utilizar elementos constituintes do mundo externo, ou seja, somente existe compreensão estética se a mesma é acordada fenomenicamente.

O conhecimento estético, portanto, é aquilo que é notado por todos, que é percebido, organizado num sistema compreensível. O belo torna-se efetivamente belo quando entendido que é, ou melhor, a beleza náo é irreal por ser impossível de conceituar, a existência dela depende da concordância de todos - óbvio que o concordar liga-se "a coisa em si" manifesta "na coisa para todos". E é justamente nesta manifestação para todos que o conhecimento estético é revelado, desta feita, as propriedades do mesmo proporcionam o retorno a metafísica, não mais medieval, agora consorciada com a razão.

A grande contribuição de Kant (1993 e 2008) foi o equilíbrio entre a razão e o não racional, ou seja, Kant não abandona o homem, não o julga como uma máquina, muito ao contrário, pois fornece as bases para a superação da própria condição humana, agregando as suas análises filosóficas elementos destoados pelos Iluministas, como a percepçáo, a imaginação e a criatividade. Os iluministas acreditavam que a liberdade (plena e absoluta) somente seria possível via racionalidade, amputavam qualquer possibilidade do ser humano manifestar-se como humano, pois eram presos aos ditames da 
razão. Kant (1993 e 2008) não abdica destes valores, mas não os exacerba, equilibra-os, definitivamente, com elementos subjetivos (próprios da condição humana).

O idealismo transcendental de Kant (2005) aponta a forma para conhecermos, afirma que o ato de conhecer depende das experiências, mas isso náo significa que se limita nas mesmas, pois o conhecimento é a relação direta do pensamento e da intuição, do empirismo e do racionalismo. Neste flerte entre o racionalismo e o empirismo Kant (2005) procurou esclarecer as condiçóes que possibilitassem a compreensão das experiências do e para conhecer. Segundo Kant (2005) a experiência somente é possível de ser conhecida quando temos elementos conceituais que promovam esse conhecimento; assim, entendemos nossas experiências a partir de nossa condição conceitual e teórica.

O mundo somente tem significado para nós à medida que compreendemos seus elementos constitutivos em múltiplas escalas e direcionamentos, isto é, Kant (2005 e 2008) afirma que somente de forma transcendental é que podemos conhecer, uma vez que essa transcendência permite aos sujeitos se compreenderem sem perderem o conhecimento de seu vínculo com o mundo.

O idealismo transcendental, segundo Schüssler (2005), é outra designação para ontologia geral, já que segundo Kant (2005) a verdade é revelada através da sensibilidade e do entendimento, necessariamente, deve abranger a universalidade. A linguagem ontológica de Kant possibilita-nos alcançarmos as intençóes quanto à verdade - dialética - que é construída na relação sujeito-mundo e mundo-sujeito, já que a relação ontológica kantiana obriga-nos a refletirmos quanto ao ser passivo e ativo diante do mundo, neste caso, será possível a formação de um juízo para que a realidade se torne efetivamente dos sujeitos, para isso faz-se necessário à conformidade dos mesmos através do entendimento, pois isso resulta nas afirmaçóes de suas atividades que possibilitam aos sujeitos que, de fato, exercem ações do e no mundo.

O ponto convergente do ser passivo e do ser ativo do e no mundo é dissertado por Kant na Terceira Crítica (2008), ou seja, a beleza. A conversão da passividade encontra-se no sublime, já a atividade do sujeito faz-se presente no belo, ou melhor:

"O sublime comove [rührt], o belo estimula [reizt]" (KANT, 1993, p. 21).

O belo apresenta-nos estímulos que independem de conceitos, de definiçôes, de delimitaçóes; isto é: 
"Não pode haver nenhuma regra de gosto objetiva, que determine através de conceitos o que seja belo. Pois todo juízo proveniente desta fonte é estético; isto é, o sentimento do sujeito, e não o conceito de um objeto, é seu fundamento determinante”. (KANT, 2008, p. 77).

O conceito de um objeto não determina o belo. É impossível determinarmos a beleza via conceitual, pois o belo existe e é. O belo é a essência que se revela e possibilita-nos pensarmos além da própria beleza, em outras palavras, a estética é o aglutinador do númeno e do fenômeno, da atividade e da passividade do sujeito - simultaneamente à aglutinação a dispersão também ocorre, pois os estímulos do belo direcionam os sujeitos a conferirem os objetos via sensibilidade e entendimento. Num primeiro momento o entendimento não é cogitado, já que a sensibilidade ancora as impressões do sujeito para posteriormente direcioná-lo ao entendimento. O belo jamais é conceituado, mas estimula o entendimento do mesmo.

Neste sentido, Kant (1993 e 2008) apresenta-nos a essência como absoluta proveniente da forma apriorística do entendimento e também pela faculdade do juízo. Destaca a relaçáo perpetua e absoluta entre o papel do sublime e do belo, como participantes efetivos na construção de nosso conhecimento; assim, pontua:

"O entendimento é o sublime, o engenho [Witz] é o belo". (KANT, 1993, p. 25).

Segundo Lyotard (1993) o desinteresse inicia a estética, sendo que o belo apraza sem conceito, no tocante, o desinteresse é a própria engenhosidade, o próprio equilíbrio entre o belo por si e em si: o númeno revelado, portanto, fenômeno.

O belo é moralmente aceito, sem refletirmos inicialmente se um objeto é ou não belo, por isso o consentimento estético surge sem questionamentos, posteriormente, utilizamos a razáo para compreendermos o belo; assim, o encantamento poderá nos assustar, pois não só aceitamos o belo como o compreendemos. O caminho do númeno para o fenômeno parte da inatividade do belo para a plena atividade do mesmo através da contemplação e da compreensão do que é belo. A razão "surge" nos questionamentos e é inevitável o desprazer, a limitação do belo, a tentativa em conceituá-lo, delimitá-lo, a torná-lo objetivo. Cede a beleza para o entendimento uma parte considerável de sua existência, neste caso, o sublime, cujo se manifesta racionalmente e opostamente ao aprazível, obriga-nos a compreender o incompreensível e faz com que a razáo seja direcionada via imaginação. O sublime aponta-nos a incompletude do ser que tenta via consórcio razão-imaginação compreender os elementos da natureza, a 
subjetividade, a materialidade e imaterialidade do e no mundo (LYOTARD, 1993; KANT 1993 e 2008).

A análise do juízo transcendental estético traz o belo como forma, como superficialidade, enquanto que o sublime é disforme. A forma do belo, a superficialidade revelada de forma imediata proporciona o prazer, já o sublime desencanta por comoção.

Esse caminho proporciona aos românticos o encantamento pela liberdade, ao mesmo tempo em que são comovidos diante da não liberdade. O belo, neste efeito, traduz a forma como representação do "ser livre" e o disforme fica por conta do horror diante da oposiçáo ao belo ou mesmo pela não compreensão daquilo que parece-nos incomensurável. $\mathrm{O}$ trilhar kantiano do belo resulta na especulação das definiçóes do que é realmente belo e o que náo é, ou melhor, o romantismo surge desta busca pela liberdade humana através da compreensão da subjetividade e da objetividade reguladas dialeticamente.

A liberdade torna-se, portanto, obrigação dos seres humanos, meta última e fundamental da existência, ancorada nas reflexóes judicativas e somente compreendida quando os sujeitos alcançarem as intençôes do belo, isto é, as formas do belo revelam-nos valores incomensuráveis que somente serão verificados ao atuarmos na direção do náo conceito, da não simplificação, ou melhor, a forma do belo nos revela os elementos necessários para nossa liberdade. O belo, definitivamente, liberta. A estética kantiana leva os românticos a compreenderem esses valores e atuarem para a propagaçáo dos mesmos (SCHÜSSLER, 2005).

Segundo Hammermeister (2006) o juízo estético é independente e, deste modo, é fundamental essa característica, pois garante a pureza da beleza e a associaçáo do belo para com o moralmente aceito. Essa aproximaçáa do belo e do aceito moralmente ou do que é bom foi também objeto de investigaçáo por parte de Berlin (2009), o qual argumentou que o aceitável moralmente é o que é bom, no caso da sociedade contemporânea a verdade, a moralidade e a beleza ligam -se, obrigatoriamente, ao acúmulo de conhecimentos, portanto, a verdade é apresentada somente por aqueles que são detentores de maior cultura e conhecimento. Houve uma substituição da beleza como fundamento para o conhecimento, de outra maneira a forma do belo é revelada (na atualidade) em associaçáo com o conhecimento, pois o belo é aquilo que apazigua (no pensar kantiano), portanto, é aquilo que revela o númeno e o transforma no fenômeno - da coisa em si para a coisa para/de/por todos.

A compreensão do belo em soma a sua importância constituinte do ser é possível, segundo Kant (2008), via centralidade do ser, ou melhor, o "eu" é retomado como centralizador das configuraçóes 
estéticas e, neste nível, revelador do que de fato é, em outras palavras, o "eu" é retomado a partir da centralidade do belo. Para compreendermos o mundo por meio da dialética eu-outros é fundamental adentrarmos na identificação dos elementos que o compóe, no nosso caso tratamos apenas da estética, do sentimento e da imaginação vinculados a concepçáo subjetivada do "eu" que se faz rogada na materialização cotidiana por meio do númeno revelado.

A estética, portanto, não é banalidade para a compreensão do desenvolvimento das ciências humanas, uma vez que a mesma a partir de Kant recolocou o "eu" no centro das atençôes epistemológicas e fomentou a ampliação da própria gnosiologia que proporcionou o significativo avanço da sensibilidade no e para o ato de conhecer; assim, o conhecimento é integral, numa totalidade irreversível e inquestionável, pois a mesma indica a relação perpétua entre o individuo e sua totalidade enquanto ser.

Deste modo, as contribuições de Kant são muitas e o século XIX colherá cada uma, seja acolhendo ou refutando seus ideários filosóficos; assim, surge a Geografia como vanguarda das ciências humanas em pleno no século XIX, sendo que isso é profundamente arraigado no ideário romântico. Antes de a Geografia tornar-se, de fato, uma ciência, a Cosmografia de Humboldt proporcionou a utilização da filosofia kantiana e romântica a partir dos estudos das paisagens. O ponto central desta afirmaçáo vincula-se a herança kantiana de sua meta-estética material, conforme Deleuze (1963) a estética formal do gosto é apresentada via fusão dos elementos do classicismo em decadência e os elementos em ascensão do romantismo, nesta seqüência a relação entre o sentimento e o entendimento fazem-se necessárias para compreendermos os pontos que alavancaram as análises paisagísticas: a aptidão do belo é fornecida pela natureza e somente conseguiremos entender o belo se não perguntarmos por ele, mas o procurarmos, já que o mesmo nos é revelado mediante o mútuo acordo entre as faculdades.

A estética vivamente é colocada como plano principal da compreensão do mundo, já que o kantismo provocou uma erupção no modo de ver e entender o mundo, em poucas décadas a firmeza das categorias, dos conceitos e das idéias dos românticos tornaram-se extremamente enraizadas no cotidiano das pessoas, inquestionavelmente o romantismo fez com que os valores subjetivos fossem valorados e o “eu" centralizado não mais como função racional, o "eu” romântico estereotipou a subjetividade e a fez tornar julgadora dos valores materiais e imateriais (SCHÜSSLER, 2005; DELEUZE, 1963). 
O caminho de Kant aos românticos levou, posteriormente, ao desenvolvimento de uma ciência que equilibrou a racionalidade e o sentimento por meio das pesquisas empíricas que eram direcionadas esteticamente.

Assim, apontamos Humboldt como detentor da capacidade (e pioneiro) para equilibrar a ciência cosmográfica via racionalidade e apresentá-la via sensibilidade, desta feita, o surgimento da Geografia passa obrigatoriamente por essa relação de equilíbrio entre a coisa em si e a coisa para os outros.

Humboldt não tinha a ambição em desvendar os caminhos históricos, suas preocupações centrais eram compreender racionalmente o mundo via estética (já que o seu pensamento cientifico era um mesclar empirista e idealista), ou melhor, não tinha essa preocupação histórica (a preocupação história, social, de Ratzel (1988)).

Ressaltamos que o elemento historicidade, em termos de paisagem, pode ser subsumido pelo volksgeist, ou seja, a cultura de um dado qualquer (que se faz presente como espírito de um povo, estruturador e estruturado), uma vez que a paisagem engloba as pessoas que a reproduzem. Desta forma, não negamos a historicidade, mas a consideramos sob o ponto de vista do produto dela; que é a marca que certo volksgeist imprime no espaço. Exemplificando: lembremos que a nacionalidade é obrigatoriamente a história de um povo, simultaneamente esse povo somente pode assim ser considerado como tal (uno) a partir da relação de sua individualidade suprimida diante da liberdade geral de sua própria história, conforme atestou Berlin (2009).

Esse espírito de um povo (volksgeist) é construído dialeticamente nas relaçooes materiais e imateriais, deste modo, o romantismo, como herança de Kant, somado as mudanças técnicas, tecnológicas, políticas e econômicas contribuíram para a retomada dos valores dados na relação da sensibilidade, entendimento e imaginação.

No Iluminismo o racionalismo era a máxima para o pleno desenvolvimento da humanidade, até mesmo a criação das artes deveria ter esse comportamento (DOBRANSKY, 1992). O romantismo rompe esses valores, não abdicando totalmente da ciência e da filosofia, pelo contrário reforça-os a partir da sensibilidade e da imaginação.

Segundo Sandler (2000, p. 22):

“O Movimento Romântico, gerado pelo século das Luzes em comunhão com a renascença, procurava uma Razão universal”. 
E encontraram visto que a supremacia do "eu" ocorreu por causa da busca das origens das dores e dos problemas individuais de uma classe muito erudita. A partir deste cenário, ainda segundo Sandler (2000, p. 23):

“[...] Paixão e Dor, até então alvo de cuidados artísticos, iriam se firmar como assuntos científicos - nas Afinidades Eletivas de Goethe, até mesmo no Frankenstein, de Mary Shelley [...] na Naturphilosophie de Goethe".

Não se tratava apenas da dor, pois o que tinha como validade universal era o sentimento, ou melhor, tudo aquilo que permitia ao homem saber, por si, que está vivo; assim, o pulsar sentimental, as tempestades de ímpetos iniciadas no "eu" forjaram as bases para a supremacia das paixóes ligadas diretamente ao desenvolvimento estético - o númeno como fenômeno por meio dos sentimentos materializados artisticamente.

Para Hammermeister $(2002,64)$ :

O romantismo tal como o idealismo pode ser compreendido como uma resposta ao dualismo kantiano do númeno e do fenômeno, de natureza e liberdade, que ainda estava para ser resolvido. [...] O próprio Kant já havia proposto que a faculdade que permite atribuir uma multiplicidade de dados sensoriais para uma única entidade perceber mesmo, ou seja, a "síntese transcendental da apercepção", deve ser considerada como "o ponto mais alto " da filosofia [...] embora esse náo seja tomado como princípio da ponte entre o númeno e o campo do fenômeno.

A ponte e ao mesmo tempo a revelação do númeno era as obras de artes, o desenvolvimento do fenômeno como ponte do "eu”. Neste sentido, não foi diferente para a Geografia, pois a mesma herdou as concepçóes de mundo e as concepçóes de ciências iniciadas nos desacordos iluministas versus românticos, prevalecendo os ideais dos segundos.

A construçáo artística romântica passa fundamentalmente pelo desdobrar sentimental iniciado na ruptura do baixo iluminismo e é revelada de uma vez por todas com a supremacia da individualidade iniciada no período denominado de Sturm und Drang (Tempestade e Ímpeto) nos anos de 1760 até o final da década de 1780. Essa ruptura fez com que os valores medievais retornassem com uma roupagem moderna, sem a religiosidade, no sentido dogmático, como soberana, pois esse novo cenário proporcionou o retorno da individualidade num projeto coletivo, isto é: o "eu" como centralidade na busca por um mundo melhor através de equilíbrios múltiplos realizados por esse "eu" que permite que sua essência alcance e se manifeste no mundo. 
Os românticos lutaram para que essa essência fosse soberana e que a mesma fosse manifestada em todo o mundo; assim, o "eu" se libertaria das amarras racionalistas quando fosse, realmente, manifestado. A partir destes objetivos os românticos somente teriam um caminho para que tais elementos se tornassem público: pelas artes.

A estética, deste modo, é o ponto fulcral para os românticos. Todo cabedal filosófico e científico tem como centralidade os elementos estéticos que se desdobraram no desenvolvimento das ciências geográficas.

\section{O COSTURAR DE HUMBOLDT: AGULHAS ROMÂNTICAS, TECIDOS COSMOGRÁFICOS}

O desenvolvimento da Geografia Moderna passa obrigatoriamente pela relação da herança kantiana nos românticos e esse conjunto de elementos influenciou decisivamente a postura cientifica de Humboldt.

A relação da estética com a postura cientifica de Humboldt culminou no desenvolvimento da ciência cosmográfica como dependente das análises paisagísticas, conseqüentemente, a fundação da Geografia Moderna. Também é importante frisarmos que o século XIX foi palco de grandes transformaçóes tecnológicas, políticas, econômicas e sociais; assim, esse cenário também influenciou Humboldt, portanto, a construção científica deste geógrafo foi um encontro revolucionário filosófico e material. Influenciado por esses ventos revolucionários (HOBSBAWN, 2005) Humboldt fez suas pesquisas a partir do equilíbrio necessário entre o pensamento kantiano, os idéias e filosofias românticas e o empirismo inglês. Segundo Capel (1983) Humboldt almejava encontrar um caminho metodológico que proporcionasse a compreensão da totalidade via unidade legislativa cosmológica, para isso a observação era fundamental, somada aos experimentos técnicos de recolhimento de amostras, comparaçóes, pesagens, testes químicos e outros.

A grande contribuição de Humboldt para as ciências em geral não se limita aos aspectos técnicos, pois o que de fato pode ser considerada uma grande contribuição foi sua cosmovisão aplicada às técnicas, uma vez que essa proporcionou o aperfeiçoamento das pesquisas cientificas ao não abandonar a subjetividade e nem privilegiar a objetividade. Humboldt trouxe para o seu cotidiano cientifico as bases kantianas filtradas pelo romantismo, desta forma, a coisa em si passou a ser "revelada" 
via metodologia e os fenômenos tiveram o entendimento a partir da relaçáo da particularidade com a universalidade.

A unidade manifesta da coisa em si exposta fenomenicamente era a paisagem. A universalidade na particularidade (e vice-versa) encontrava-se para Humboldt nas paisagens. O entendimento das paisagens tem fundamentos filosóficos que equilibram a subjetividade e a objetividade; assim, Humboldt não elege a paisagem como unidade de pesquisa aleatoriamente, a mesma oferece todos os elementos possíveis, os quais faziam parte de sua bagagem teórico-metodológica, dentre os quais destacamos os aspectos físicos da natureza e os aspectos subjetivos que buscavam compreende-la, ou melhor, as impressões sensíveis, a imaginação e a criatividade, em resumo, os elementos subjetivos encontravam-se "agrupados" esteticamente. Desta forma, a paisagem através das pesquisas forneceria respostas para as questóes formuladas por Humboldt a partir dos fenômenos reveladores da universalidade na unidade.

Humboldt (1964) entrelaça os sentimentos e a razão; assim, ao descrever as paisagens enumera os aspectos estéticos que produzam comoção, isto é, a beleza, no sentido kantiano, não depende de conceituação, pois o belo É; todavia, a partir do belo Humboldt se comove - isso significa que o belo é imbricado a condição sublime, já que o "espanto" para com o belo - revela-nos condiçôes próprias do sublime kantiano. A estética de Humboldt não abandona a estética de Kant, ou seja, as resoluçóes das antinomias da liberdade e do gosto prevalecem através da resolução destas nas quais a harmonia do organicismo surge como solução apoiada na paisagem.

Deste modo, a paisagem é, sem dúvida, a centralidade do aperfeiçoamento e do conseqüente desenvolvimento da ciência geográfica. Humbodt (1964) parte da relação estética da paisagem; assim, ele destaca os sentimentos a partir dos elementos paisagísticos e os elementos paisagísticos a partir dos sentimentos, como exemplo: “[...] $\mathrm{O}$ mundo vegetal actua [...] sobre nossa imaginação pela sua mobilidade e magnitude". (HUMBOLDT, 1964, p. 286).

Neste ínterim entendemos que as manifestações fenomênicas dependem também da relação numênica, pois o fenômeno por si nada nos revela, já que o ponto nevrálgico desta revelação parte do "eu". Parte do "eu”, porém não se fixa no mesmo, não se trata de um engessamento, sim de um ponto de partida que dialeticamente retorna, passando pelas paisagens e fomentando nos indivíduos impressóes e compreensões destes elementos geográficos no mundo. As paisagens, segundo Humboldt, nos são reveladas mediante o belo constituindo o campo do fenômeno sem serem assim designadas. Tal 
como em Kant na CJ, para Humboldt (1964) e nos quatro volumes do Cosmos, a beleza significa a harmonia da imaginação e do entendimento, trata-se de algo que independe de conceitos, o belo em si e por si nos revela a harmonia de forma instantânea, sem pensarmos conceitualmente, isto é, o belo nos surge.

A estética de Humboldt, como herança da estética de Kant, proporcionou a retomada do organicismo da Idade Média, já que a idéia de organicismo era compreendida como um todo orgânico direcionado para uma finalidade comum, pois a estética de Humboldt tinha como principal característica a harmonia. Essa visão organicista possibilitou a Humboldt (1964, 1855 e 1875) o desenvolvimento de uma metodologia analítica universalista; assim, dialeticamente ao fazer seus estudos cosmográficos o mesmo buscava compreender os elementos sempre em conjunto, a unidade como parte do todo e o todo como soma das partes.

A herança kantiana, pelo fim da metafísica (LEBRUN, 1993), influenciou diretamente a postura cientifica de Humboldt, pois o equilíbrio entre a metafísica da natureza e dos costumes proporcionou a Humboldt a uma postura cientifica calcada na cientificidade sem abrir mão dos elementos imensuráveis, dentre os quais os sentimentos. $\mathrm{O}$ orgânico em Humboldt é o todo e a totalidade que tem em si e por si a própria finalidade ao mesmo tempo em que é também o meio, causa e conseqüências simultaneamente.

O organismo em Humboldt é a totalidade, o que, de fato, permitiu constituir um corpo sistemático de conhecimentos os quais, posteriormente, permitiram o desenvolvimento e sistematizaçáo dos conceitos, categorias e temas próprios para a ciência geográfica.

Neste sentido, a finalidade organicista não é finalidade metafísica, uma vez que se trata de uma postura crítica diante dos acontecimentos do mundo; assim, suas indignações na sua obra "Ensaio político sobre o reino da Nova Espanha” quanto a escravidão são provas suficientes para entendermos Humboldt a partir da insatisfação social romântica e a utilizaçáo de seus estudos com a finalidade de entender e almejar a harmonia no mundo.

Assim para Vitte (2008, p. 61):

Para Marques Filho (1987), a concepçáo de organismo rompe com o mecanicismo newtoniano, levando a estruturaçáo da natureza como um sistema, como uma totalidade. Para Lebrun (1993) o organismo como totalidade pressupóe a independência da Natureza e do Espaço em relação à razão e mais do que isto, fundamenta-se na tese da epigenia, termo criado por William 
Harvey em 1651 (Crampe-Casnabet, 1994) que advoga contra o préformacionismo de base mecanicista, e postula que o ser forma-se a partir de uma matéria indiferenciada. $\mathrm{O}$ ser vivo, segundo a tese epigênica, não se forma a partir de planos pré-estabelecidos, mas a partir da natureza.

As influências de Humboldt para a Geografia, a partir da estética kantiana e do legado romântico na confluência da paisagem, são: a visão crítica, a sistematizaçáo do conhecimento geográfico, a universalizaçáo dos conceitos geográficos, o advento da categoria paisagem e a complementaridade da relação contínua homem e natureza. Neste sentido, ainda entendemos que a estética kantiana em Humboldt resultou no desenvolvimento da Geografia a partir da ampliaçáo dos estudos das paisagens.

Tais estudos paisagísticos refletiam a tentativa em por fim ao desequilíbrio entre ciências e imaginação, já que para Humboldt (1964 e 1964a), a compreensão do mundo somente seria possível através da sistematização cientifica e também do entendimento do imensurável, porém pronto para ser descrito. Ricotta (2003, p. 21) assinala: "Humboldt domina a aridez das descriçóes científicas para fixar a 'impressão viva' da Natureza”.

O imensurável é na verdade as impressóes tanto do belo quanto do sublime. Humboldt a partir da sistematização cientifica busca elementos precisamente estéticos; assim, segundo Ricotta (2003), Humboldt cultivar a estética objetivando a realidade do mundo natural através das impressóes, sensações e sentimentos.

Ao legado de Humboldt devemos ainda acrescentar, conforme Moreira (1981), a inseparabilidade do homem e da natureza, chamado por Moreira (1981) de geografia-ecologia. Para Moraes (1989, p. 110) a grande contribuição de Humboldt está na: “[...] busca da unidade da natureza

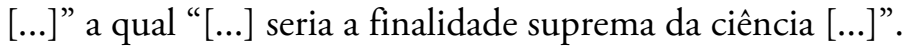

Conforme Moreira (2006, p. 23) o legado de Humboldt está na sua concepção da relação do homem como mediador na natureza; assim: "Já para Humboldt, a geografia centra-se também no homem, mas este compreende-se no interacionismo das esferas com primado no papel mediador do orgânico".

Segundo Moraes (1989) a contribuição de Humboldt para a Geografia está na delimitação do que seja Geografia a partir da definição da mesma como ciência sintética, as análises das conexóes dos fenômenos e a idéia de unidade da natureza e da terra. 
Ainda segundo Moraes (1989) Humboldt parte da observação da paisagem por meio da contemplação da mesma a qual transmite para aquele que a contempla sensaçóes relacionadas às suas representações anteriores. A contemplação somente é possível pela relação entre o belo que harmoniza e o sublime que contrasta logo a natureza é direcionada para o afã do homem, isso significa que o homem é intermediário entre o mundo que lhe parece e o mundo que é. Os desejos dos homens somente têm sentidos quando a natureza harmoniza e o sublime "espanta".

O conceito de natureza em Humboldt é a imagem da evolução, de um transformar-se que encontra na forma a imagem integradora de todo o seu processo de reprodução. Norteada por um princípio elementar, fundamental, a natureza é dinâmica e se dispõe em harmoniosa construção entre o invariável e o particular. Esse articular da natureza corresponde à visão de Goethe. (SILVEIRA, 2008, p. 81).

Assim, a dinâmica da natureza revela aos homens as suas próprias condiçóes seja pela comoção ou pelos estímulos, conforme Kant na CJ. As impressóes do real físico poderão ser harmonizadas no real psíquico ou desarmonizadas, já que a relação entre o homem e a natureza é extremamente íntima e só existe um e o outro por causa desta intimidade. Tal intimidade é revelada através da exposição da paisagem; assim, ao olharmos para um cenário podemos convertê-lo, por meio do belo ou do sublime, em paisagem. Lembrando que a paisagem ideal para Humboldt é a paisagem harmoniosa, aliás condição hereditária do romantismo.

A paisagem humboldtiana é herança direta do romantismo, já que a paisagem romântica é essencialmente harmônica como aponta Claval e Entrikin (2004):

"Numa perspectiva romântica, ela também pode ser vista como reflexo de uma harmonia profundamente enraizada nos diferentes componentes da natureza (relevo, paisagens vegetais, etc...) e a paisagem cultural”. (p. 255).

A harmonia entre os elementos naturais e culturais em Humboldt influencia, posteriormente, demais geógrafos, com as teorias sistêmicas (na qual o equilíbrio entre os elementos do sistema é fundamental), a geografia teorética (que através do equacionamento, do planejamento e das açóes pela Geografia vislumbrava relativa harmonia), a geografia crítica (a qual de forma contestadora objetivava um mundo mais justo, mais equilibrado no sentido material, político, social e econômico, em outras palavras, mais harmônico), a geografia cultural (que busca entender as relaçóes dos indivíduos pelo 
equilíbrio sócio-espacial); enfim, a harmonia de Humboldt foi e é a base da Geografia, que independente de escolas filosóficas, tem como finalidade máxima a compreensão do mundo, do homem e a busca qualificada por uma harmonia que providencie justiça, saúde, igualdade, liberdade, democracia, cidadania, qualidade de vida, conservação e preservação dos recursos naturais, etc...

A harmonia em Humboldt parte da relação dialética entre o mundo, enquanto paisagem, e o sujeito, enquanto contemplador. O próprio Humboldt (1874, p. 03) afirma:

Sigo o objetivo que propus e não tenho me desesperado para chegar, conforme minhas forças e meu estado atual de ciência. Conforme o plano que tracei, nos dois tomos do Cosmos publicados até hoje considero a Natureza em uma dupla perspectiva: reproduzindo-a primeiramente no seu aspecto exterior e puramente objetivo, e depois pintando sua imagem refletida no interior do homem através dos sentidos. Deste modo, tenho buscado os traços da influência que tenham exercido nas idéias e nos sentimentos dos diferentes povos.

Desta maneira, Humboldt destaca a paisagem como elemento unificador e revelador, pois o aspecto visível é objetivado enquanto os aspectos subjetivos são representados na relação objetividadesubjetividade revelado via paisagem. Humboldt acredita que as paisagens interferem nos sentimentos e até mesmo na imaginação de diferentes povos. Já que as imagens capturadas são processadas subjetivamente a partir da relaçáo da cultura imaterial e material.

O estudo das paisagens e os elementos que a compóe são, portanto, outro ponto fundamental do legado de Humboldt para a Geografia. O cosmógrafo alemáo construiu o conceito de paisagem de forma dialética, já que levou em consideração a imaterialidade e a materialidade na recepção destes pontos no sujeito ao mesmo tempo em que esse sujeito tem todas as condiçóes para interpretar e representar essa paisagem.

Isto colocado, entendemos que a importância dada por Humboldt as paisagens se deve a dois fatores: necessidade de exatidáo para descrever as diferentes regiōes do globo terrestre; e necessidade de exatidão conceitual e categorial dos elementos geográficos.

Percebam essas necessidades de exatidão não são simples caprichos "positivistas" ou "realistas", são realmente pontos fundamentais na descrição, interpretação e representação das paisagens, pois Humboldt precisava explicar o mundo (orgânico e inorgânico) para isso era urgente o desenvolvimento de uma metodologia que possibilitasse essa tarefa. 
Sua elaboração e sua prática metodológica não partem de simples descriçóes, já que o ato de descrever as paisagens liga-se aos elementos estéticos herdados de Kant e do romantismo alemão.

“[...] Assim, através de Forster, de Goethe e da literatura pré-romântica, o sentimento da natureza foi elevado por Humboldt a uma clara expressão científica e difundido, por seu grande prestígio, a um público amplo" (CAPEL, 2004, p. 18).

Capel escreve que os pré-românticos influenciaram Humboldt, só que o mesmo esqueceu que o movimento romântico também exerceu grande influência no cosmógrafo alemão.

Humboldt conseguiu transformar o sentimento da natureza em natureza, isto é, as paisagens que antes eram idílicas cantadas, pintadas e recitadas por muitos artistas (deste período) foram "convertidas" em peças cientificas, todavia as mesmas somente seriam cientificamente compreendidas, conforme Humboldt (1855), se aglutinasse os elementos orgânicos e inorgânicos; assim, as paisagens de Humboldt soma a objetividade e a subjetividade. Não existe, neste sentido, paisagem sem as impressões e representaçóes. As paisagens são compreendidas esteticamente. $\mathrm{O}$ valor estético liga-se, diretamente, a harmonia do belo, logo a ciência em Humboldt não depende apenas das condiçóes rígidas do método, já que os elementos subjetivos são indispensáveis para compreendermos a totalidade; assim:

Estas relaçóes seriam suficientes para mostrar o entendimento da ciência a qual tento aqui definir os limites, mas o homem sensível às belezas da natureza ainda pode encontrar a explicação da influência que exerce o aspecto da vegetação sobre o gosto e imaginação das pessoas. Agrada examinar em que consiste o nome da característica da vegetação e a variedade de sensaçóes que produz na alma de quem contempla (HUMBOLDT \& BONPLAND, 1805, p. 30).

Humboldt e Bonpland (1805) enumeram a sensibilidade e a imaginação como ponto fundamental na explicação cosmográfica de mundo, pois o imaterial pode revelar o material, ou seja, o invisível revela o visível através de elementos não mensuráveis, mas que possibilitam revelar-nos elementos que desconsideraríamos se fossemos positivistas, dentre os quais a sensibilidade e a imaginação.

Humboldt equilibra a razão e a emoção, não permite que um se sobreponha ao outro. Para Ricotta (2003) o Cosmos de Humboldt parte da definiçáo da atuação dos aspectos físicos da natureza sobre os homens intermediados pela moral. A moral em Humboldt é, sem dúvida, herança da moral kantiana a partir da cobrança que o próprio Humboldt se faz quanto ao seu dever em compreender o 
mundo. A finalidade de Humboldt parte da moralidade, não é possível separarmos a estética da moral, entrelaçam-se e tornam-se indistinguíveis na prática laboral de Humboldt. Essa obrigação (uma espécie de superego) quanto ao dever é própria dos iluministas que foram transmitidas e modificadas pelos românticos, pois os primeiros consideram fundamental a razáo para entender e modificar o mundo, enquanto que os últimos não consideravam a razão infalível, substituindo-a pelos aspectos subjetivos, como a emoção.

A moral em Humboldt é herdada pelas futuras geraçôes de geógrafos e pelas muitas escolas geográficas, isto é, o dever cientifico de ir além da compreensão de mundo, a aplicação dos conhecimentos geográficos para o melhoramento do mundo; assim, entendemos que todas as escolas geográficas partam deste principio essencialmente moralizante. Desde a escola teorética-quantitativista (através da exatidão matemática, pelo planejamento melhoria o mundo) até mesmo a escola humanistaculturalista (por meio dos estudos subjetivos e culturais dos indivíduos a Geografia será capacitada para melhorar alguma coisa no mundo). Para Ricotta (2003, p. 105):

"Humboldt formula que a ciência poética da Natureza deve relacionar-se com a maneira de agir, quer dizer, com os princípios e métodos que visam a conceder a convergência do intelectual com a sensibilidade e a moral-pragmática”.

Segundo Moreira (2006) em Humboldt o homem é o centro de suas preocupaçóes, desde que o mesmo seja estudado na perspectiva de uma natureza holística; assim, a interação do orgânico e do inorgânico, herança de Schelling, faz-se evidente na construção moral revelada na interpretação estética da paisagem.

Para Gonçalves (2005) a natureza em Schelling parte da infinitude revelada no finito, neste caso, nos sujeitos, os quais holisticamente têm a duplicidade do espírito e da matéria que produz nestes sujeitos as condiçóes imagéticas de suas singularidades, quando na verdade são movidos pela generalidade do espírito (atividade uma), ou seja:

A conclusão a que chega Schelling no texto de 1800 é de que a atividade uma, presente tanto na natureza quanto no espírito, é uma atividade originalmente estética, no sentido de uma criação poiética propriamente dita. Essa estética ampliada para além dos limites aparentes do espírito, ou seja, para a natureza como totalidade, faz com que Schelling de fina a filosofia não mais como sinônimo de Filosofia da Natureza, mas também como sinônimo de filosofia da arte. (GONÇALVES, 2005, p. 87). 
A ampliação desta estética é realizada por Humboldt em todas as suas obras, de nenhuma maneira ele abandona os ideais românticos e nem foge das heranças iluministas, o que ocorre com Humboldt é o equilíbrio filosófico e geográfico, ou melhor, nunca abandonou sua metodologia harmônica dentro das perspectivas morais. A influência de Humboldt ainda continua de várias formas, seja diretamente ou indiretamente. A relação Kant, romantismo, estética e os primórdios da Geografia em Humboldt forneceram uma estrutura básica da qual a Geografia não pode se desvincular, pois isso se trata de herança epistemológica e refutá-la seria negar a própria história da ciência geográfica.

\section{CONCLUSÃO}

A herança romântica germânica proporcionou a Geografia, antecedida pela filosofia kantiana, a sua fundação e, posteriormente, o desenvolvimento de suas categorias; assim, num primeiro momento a categoria paisagem proporcionou a unidade conceitual e categórica necessária para formação de uma ciência baseada numa cosmovisão própria.

A leitura de Kant foi providencial para os românticos germânicos que retomaram valores apagados ou subtraídos pela filosofia e ciência iluminista. O elo entre Kant e os românticos foi, sem dúvida, a estética, já que essa proporcionou relaçôes subjetivas e objetivas para que fosse possível compreender a totalidade no/do e para o mundo.

A paisagem, neste contexto, é a soma da estética e da ciência, do númeno e do fenômeno, da coisa em si e da coisa para todos. A paisagem, a partir de Humboldt, ao ser estudada proporciona uma visão científica mais ampla, pois não permite que seus elementos se camuflem ora subjetivamente ora objetivamente.

Entendemos que o pensamento de Humboldt inaugurou a própria dialética geográfica, já que o mesmo busca equilibrar os contrários e suas técnicas vão além do quantitativismo.

Estudar Kant e Humboldt é um desafio constante para os geógrafos, pois os mesmos apresentam dificuldades que devem ser detalhadamente trabalhadas e tais detalhes nos revelam elementos fundamentais para compreendermos a epistemologia geográfica e até mesmo indicar pontos que aperfeiçoem nossa ciência. 


\section{REFERENCIAS BIBLIOGRÁFICAS}

BERLIN, I. Idéias políticas na era romântica. Ascensão e influência no pensamento moderno. São Paulo: Companhia das Letras, 2009.

CAPEL, H. Filosofia e ciência na Geografia contemporânea: uma introdução à Geografia. Vol. I. Maringá: Massoni, 2004.

CAPEL, Horácio, Filosofia e ciencia en la Geografia contemporánea. Una introducción a la Geografia. Barcelona. Ed. Barcanova, 1983

CLAVAL, P; ENTRIKIN, N. Lieu et paysage entre continuité et changement: perspectives sur l'approche culturelle. In: BENKO, G; STROHMAYER, U. Horizons géographiques. Paris: Breal, 2004. p. 241-289.

DARDEL, E. L'homme et la terre. Paris : CTHS, 1990.

DELEUZE, G. e GUATTARI, F. O que é a Filosofia? Rio de Janeiro: Ed. 34, 1992.

DELEUZE, G. La philosophie critique de Kant. Paris : PUF, 1963.

DELEUZE, G. Para ler Kant. Rio de Janeiro: F. Alves, 1976.

DOBRANSKY, E. A. No tear de Palas: imaginação e gênio no século XVIII - uma introdução. Campinas: Papirus/Editora da Unicamp, 1992.

GOMES, P.C.C. O conceito de região e sua discussão. In: CASTRO, I. et al. (org.). Geografia: conceitos e temas. Rio de Janeiro: Bertrand Brasil, 1995.

GONÇALVES, M. F. Schelling: filósofo da natureza ou cientista da imanência? In: PUENTE, L. R.; VIEIRA, L. A. As filosofias de Schelling. Belo Horizonte: Edufmg, 2005. p. 69-90.

HAMMERMEISTER, K. The german aesthetic tradition. New York : Cambridge, 2006.

HELFERICH, G. O Cosmos de Humboldt: Alexander von Humboldt e a viagem à América Latina que mudou a forma como vemos o mundo. Rio de Janeiro: Editora Objetiva, 2005.

HOBSBAWN , Erick. A Era das Revoluçóes: Europa 1789-1848. São Paulo: Paz e terra, 2005.

HÖFFE, O. Immanuel Kant. São Paulo: Martins Fontes, 2005.

HUMBOLDT, A. Cosmos, ensayo de una descripción física del mundo, Madrid: Imprenta de D. Jose Trujillo, 1852.

HUMBOLDT, A. Cosmos, ensayo de una descripción física del mundo. Vol. II. Madrid: Gaspar e Roig Editores, 1874. 
HUMBOLDT, A. Cosmos, ensayo de una descripción física del mundo. Vol. III. Madrid: Gaspar e Roig Editores, 1874a.

HUMBOLDT, A. Cosmos, ensayo de una descripción física del mundo. Vol. IV. Madrid: Gaspar e Roig Editores, 1875a.

HUMBOLDT, A. Cosmos, ensayo de una descripción física del mundo. Vol I. Bélgica: Eduardo Perié Editor, 1875.

HUMBOLDT, A. Cosmos. Essai d'une description physique du monde. Tome Deuxiéme. Paris, Gide Et J. Baudry Éditeurs, 1855.

HUMBOLDT, A. Cuadros de la natureza. Madri: Catarata, 2003.

HUMBOLDT, A. Quadros da natureza. São Paulo: W.M. Jackson, 1950. 2v

HUMBOLDT, A. Quadros da natureza. Vol. I São Paulo: W.M. Jackson, 1964

HUMBOLDT, A. Quadros da natureza. Vol. II. São Paulo: W.M. Jackson, 1964a

HUMBOLDT, A.; BONPLAND, A. Essai sur la géographie des plantes. Paris : Chez Levrault, Schoell et Compagnie, 1805.

KANT, I. Anthropologie du point de vue pragmatique. Paris : J. Vrin, 1964.

KANT, I. Crítica da faculdade do juízo. Rio de Janeiro: F. Universitária, 2008.

KANT, I. Crítica da Faculdade do Juizo. Rio de Janeiro: Forense, 1993b.

KANT, I. Crítica da razão prática. São Paulo: Martin Claret, 2005.

KANT, I. Crítica da razão pura. São Paulo: Martin Claret, 2003.

KANT, I. Géographie. Paris: Aubier, 1999.

KANT, I. Observaçôes sobre o sentimento do belo e do sublime. Campinas: Papirus, 1993.

LEBRUN, G. Kant e o fim da metafísica. São Paulo: Martins Fontes, 1993.

LEBRUN, G. Sobre Kant. São Paulo: Iluminuras, 2001.

LYOTARD, J.-F. Lições sobre a analítica do sublime. São Paulo, Papirus, 1993.

MENDOZA, J. G; JIMÉNEZ, J. M.; CANTERO, N. O. El pensamiento geográfico. Madrid: Alianza Editorial, 1988.

MORAES, A. C. R. A Gênese da Geogafia Moderna. São Paulo: Hucitec-Edusp, 1989.

MOREIRA, R. O círculo e a espiral - para a crítica da geografia que se ensina - 1. Niterói: AGB Niterói, 2004. 
MOREIRA, R. $O$ discurso do avesso (para a crítica da Geografia que se ensina). Rio de Janeiro: Dois Pontos, 1987.

MOREIRA, R. O que é Geografia? São Paulo: Brasiliense, 1981.

PRATT, M. L. Os olhos do império: relatos de viagem e transculturação. Bauru: EDUSC, 1999.

PROENÇA FILHO, D. Estilos de época na literatura. São Paulo: Ática, 1995.

QUAINI, M. A construção da Geografia Humana. São Paulo: Paz e Terra, 1992.

RATZEL, F. El territorio, la sociedad y el Estado. In: MENDOZA, J. G. \& JIMÉNEZ, J. M. \& CANTERO, N. O. El Pensamiento Geográfico. Madrid: Alianza Editorial, 1988. p. 193-204.

RICOTTA, L. Natureza, ciência e estética em Alexander Von Humboldt. Rio de Janeiro: Mauad, 2003.

SANDLER, P. C. Goethe e a psicanálise. Rio de Janeiro: Imago, 2001.

SCHÜSSLER, I. Art et liberte dans l'idealisme transcendental. Kant et Schiller. Lausanne : Payot, 2005.

SILVEIRA, R. W. D. As influências da filosofia kantiana e do movimento romântico na Gênese da Geografia Moderna: os conceitos de espaço, natureza e morfologia em Alexander von Humboldt. Campinas: UNICAMP, 2008. (dissertação de mestrado).

VITTE, A. C. A categoria paisagem e o desenvolvimento da geografia física. Revista Mercator. Ceará: Revista de Geografia da UFC, ano 06, número 11, 2007. p. 71-78. Disponível em http://www.mercator.ufc.br/index.php/mercator/article/view/58/33 <Acessado em 24-09-2008).

VITTE, A. C. A terceira crítica kantiana e sua influência no moderno conceito de Geografia Física. In: Geousp-Espaço e Tempo. São Paulo: USP. N. 19, p. 33-52, 2006.

VITTE, A. C. Influência da estética Kantiana na gênese da geografia física. VII ANPEGE. Rio de Janeiro, 2007

VITTE, A. C. Influências da Filosofia Kantiana na Gênese da Geografia Física. Mercator - Revista de Geografia da UFC, ano 07, número 14, 2008, p. 57-66. Disponível em http://www.mercator.ufc.br/ $<$ Acessado em 23-01-2010). 